\title{
The role of cyclin-dependent kinase 5 and a novel regulatory subunit in regulating muscle differentiation and patterning
}

\author{
Anna Philpott, ${ }^{1}$ Elena B. Porro, ${ }^{2}$ Marc W. Kirschner, and Li-Huei Tsai ${ }^{2}$ \\ Department of Cell Biology and ${ }^{2}$ Department of Pathology, Harvard Medical School, Boston, Massachusetts 02115 USA
}

Cyclin-dependent kinase 5, coupled with its activator p35, is required for normal neuronal differentiation and patterning. We have isolated a novel member of the $\mathrm{p} 35$ family, $\mathrm{Xp} 35.1$, from Xenopus embryos which can activate cdk5. Xp35.1 is expressed in both proliferating and differentiated neural and mesodermal cells and is particularly high in developing somites where cdk5 is also expressed. Using dominant-negative cdk5 (cdk5 DN), we show that cdk5 kinase activity is required for normal somitic muscle development; expression of cdk5 DN results in disruption of somitic muscle patterning, accompanied by stunting of the embryos. Using explants of animal pole tissue from blastula embryos, which will differentiate into mesoderm in response to activin, we show that blocking cdk5 kinase activity down-regulates the expression of the muscle marker muscle actin in response to activin, whereas the pan-mesodermal marker Xbra is unaffected. Expression of MyoD and MRF4 (master regulators of myogenesis) is suppressed in the presence of cdk5 DN, indicating that these myogenic genes may be a target for cdk5 regulation, whereas the related factor Myf5 is largely unaffected. In addition, overexpression of Xp35.1 disrupts muscle organization. Thus, we have demonstrated a novel role for cdk5 in regulating myogenesis in the early embryo.

The sequence data described in this paper have been submitted to GenBank under accession no. AF000951.]

[Key Words: cdk5; Xp35.1; muscle; myogenesis; mesoderm; Xenopus]

Received February 26, 1997; revised version accepted April 21, 1997

Development is a complex but well-ordered process where division and differentiation exist in a delicate balance. During early development, division predominates producing the cell mass and cell number required for later induction and patterning. As development progresses, inductive events result in ordered cell and tissue commitment and differentiation, processes governed by differing levels of extracellular signaling molecules. These signaling molecules trigger cascades of differentiation-specific gene expression, coordinated by families of transcription factors. One of these differentiation-specific genes shown recently to play a role in development of the nervous system is cyclin-dependent kinase 5 (cdk5).

$c d k 5$ was initially isolated because of its homology to other members of the cyclin-dependent kinase family (Meyerson et al. 1992). Although the other cdks act as master regulators of cell cycle progression, $\mathrm{cdk} 5$ in the mouse embryo is found at its highest levels in the largely differentiated central nervous system (CNS), while its

${ }^{1}$ Corresponding author.

E-MAIL philpott@bcmp.med.harvard.edu; FAX (617) 432-0420. associated kinase activity is only detected in differentiating neurons (Lew et al. 1992; Shetty et al. 1993; Tsai et al. 1993). In contrast to other cdks, cdk5 kinase activity is not stimulated by an associated cyclin but by another class of activator, typified by p35 (Ishiguro et al. 1994; Lew et al. 1994; Tsai et al. 1994). In mouse embryos, p35 is found exclusively in postmitotic neurons where its presence correlates closely with cdk5 kinase activity (Lew et al. 1994; Tsai et al. 1994). A direct role for cdk5 in neural differentiation has been demonstrated experimentally; in primary cultures of rat cortical neurons, a kinase-dead dominant-negative mutant of $c d k 5$ has been shown to inhibit neurite outgrowth (Nikolic et al. 1996) while overexpression of $\mathrm{cdk} 5$ with p35 in these neurons results in enhanced neurite outgrowth. More recently, a $c d k 5$ null mutant mouse has been described that exhibits late embryonic and perinatal lethality accompanied by defects in the organization of the brain, particularly the cortex and cerebellum (Ohshima et al. 1996). Moreover, mouse strains lacking $p 35$ exhibit cortical lamination defects, seizures, and adult lethality (Chae et al. 19971.

While a role for cdk 5 has been clearly demonstrated in neurite outgrowth, a late stage of neurogenesis, and in 
patterning of the cortex and cerebellum, little is known about whether it has a function earlier in development. Early developmental stages are difficult to study in mammals because of the small size and inaccessibility of the embryos, so we have turned to a more experimentally tractable system, namely, embryos of the frog Xenopus laevis. Recently, cdk5 has been cloned from Xenopus and shows a wide tissue distribution in the early embryo (Gervasi and Szaro 1995). In mammals, although a high level of cdk 5 kinase activity has only been demonstrated in differentiating neurons of the CNS, lower levels are found extensively in many tissues (Tsai et al. 1993), and it is possible that $\operatorname{cdk} 5$ has a role in regulating the differentiation of a wide variety of cell types. Here we describe the cloning of a novel activator of cdk 5 expressed in muscle of the early Xenopus embryo and demonstrate a new role for $c d k 5$ and its activator Xp35.1 in regulating embryonic muscle formation.

\section{Results}

\section{Cloning of a novel member of the cdk5 activator} family

To identify the Xenopus homolog of the neural-specific activator of $c d k 5$ (called $p 35$ in mammals), we screened a Xenopus stage 28 head cDNA library at low stringency with partial human $p 35$ (hp35) cDNA (Tsai et al. 1994) corresponding to the carboxy-terminal $600 \mathrm{bp}$. After screening 500,000 phage plaques, two positive clones were obtained. One of them contained a $1.5-\mathrm{kb}$ insert encoding a partial open reading frame (ORF) of $\sim 190$ residues, which shared significant homology to the cdk5 binding and activation domain of $h p 35$ (L.-H. Tsai, unpubl.). The second clone contained a $2.5-\mathrm{kb}$ insert encoding a complete ORF displaying a high degree of homology to human p35 throughout its length and is distinct from the first clone. These two clones are thus named $X p 35.1$ and Xp35.2, respectively. Five different cDNA libraries made from RNA of different Xenopus embryonic stages were screened for full-length $X p 35.1$, and none of them provided any additional coding information. To obtain the $5^{\prime}$ end of Xp35.1, RACE (rapid amplification of $\underline{\mathrm{c} D N A}$ ends) was performed using RNA from stage 32 embryos (see Materials and Methods). A RACE product of $160 \mathrm{bp}$ contained $91 \mathrm{bp}$ of additional 5' sequence that showed homology to $h p 35$. Finally, the initial library clone was used as a probe to screen a Xenopus genomic library at high stringency. Many positives were obtained, and for the secondary screen the new RACE-obtained fragment was used as a probe. Four of the positives were subcloned and sequenced, and all displayed a complete match with the initial cDNA clone and the RACE fragment of Xp35.1. As is the case with mouse $p 35$ (Chae et al. 1997), the coding region of Xp35.1 does not contain introns. The predicted 293-amino-acid residues ORF of Xp35.1 (Fig. 1) shows an overall $68 \%$ identity to $h p 35$ and $56 \%$ identity to human $p 39$ (Tang et al. 1995), a homolog of $p 35$ recently isolated from a human hippocampus cDNA library. The Xp35.2 gene seems more closely related in expression pattern to the p35 described in mammals and is being studied further (data not shown). We focus on the characterization of Xp35.1 in this report.

\section{Xp35.1 is expressed in early neural tissue and in developing somites}

To determine developmental expression of $X p 35.1$ we have used a highly sensitive quantitative reverse transcription and PCR assay (RT-PCR) (see Materials and Methods) using ornithine decarboxylase which is constantly expressed as a loading control (Isaacs et al. 1992) (Fig. 2A). Xp35.1 message is present only at very low levels maternally, but it increases after the midblastula transition (MBT), rising to a peak at around stage 35 in the swimming tadpole stage embryo. Thus, Xp35.1 is present at its highest levels at a time in development when extensive differentiation of a variety of tissues, including nerve and muscle, is occurring (Nieuwkoop and Faber 1967).

A Xenopus homolog of $c d k 5$ has been isolated (Gervasi and Szaro 1995) that shows a remarkable $98 \%$ identity to the human protein at the amino acid level. Developmental expression of Xenopus cdk5 was investigated by Northern blot (Gervasi and Szaro 1995), where message was shown to begin accumulating shortly after the MBT. To investigate the expression of the cdk 5 protein, we used a monoclonal antibody, DC17 (Tsai et al. 1993), raised against human cdk5, that recognizes human, mouse, Drosophila and Caenorhabditis elegans cdk5 (L.H. Tsai, unpubl.), to detect the Xenopus cdk5 protein in Western blots of developmentally staged embryos (Fig. 2B). A single band of the predicted molecular mass, 33 $\mathrm{kD}$, is detected, which we conclude is Xenopus cdk5. cdk5 is present at approximately constant levels throughout development. Interestingly, cdk5 protein is detected even before the MBT, indicating a maternal stockpile of the protein. Similar results were obtained by probing a Western blot of developmentally staged Xenopus embryos with an antibody against the carboxyl terminus of human $\operatorname{cdk} 5(\mathrm{C} 8$, Santa Cruz), which shares 7 out of 8 amino acids with its Xenopus homolog, thus confirming the identity of this $33-\mathrm{kD}$ band /data not shown).

To investigate both spatial and temporal expression of Xp35.1 we performed in situ hybridization using an antisense probe to the carboxy-terminal portion of the gene (Fig. 3A). Xp35.1 message is first detected in the blastula embryo, viewed here from the vegetal pole (panel i, lower right), where it is found at low levels throughout the animal hemisphere but is more abundant in the marginal zone, a ring of tissue around the circumference of the embryo fated to become mesoderm (Dale and Slack 1987). As gastrulation begins, Xp35.1 remains most strongly in a ring surrounding the blastopore, which corresponds to the region of involuting mesoderm (panel i, upper left).

At early neural plate stages, Xp35.1 is expressed extensively over the dorsal surface of the embryo /data not 
A

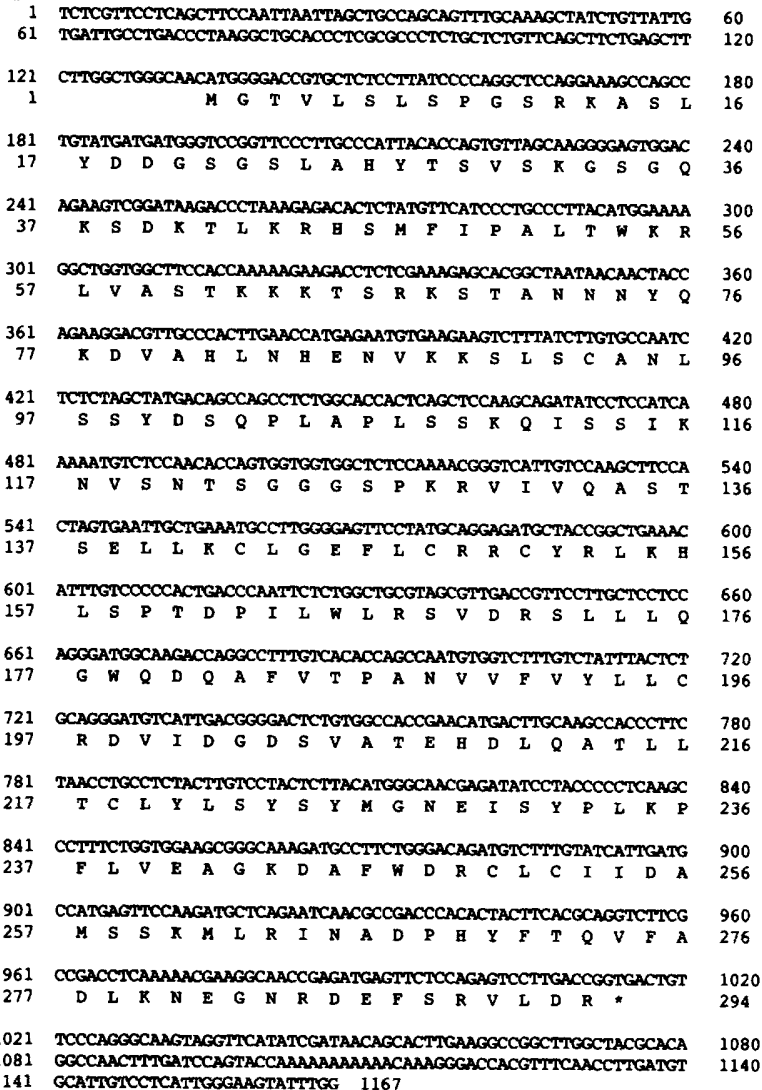

B

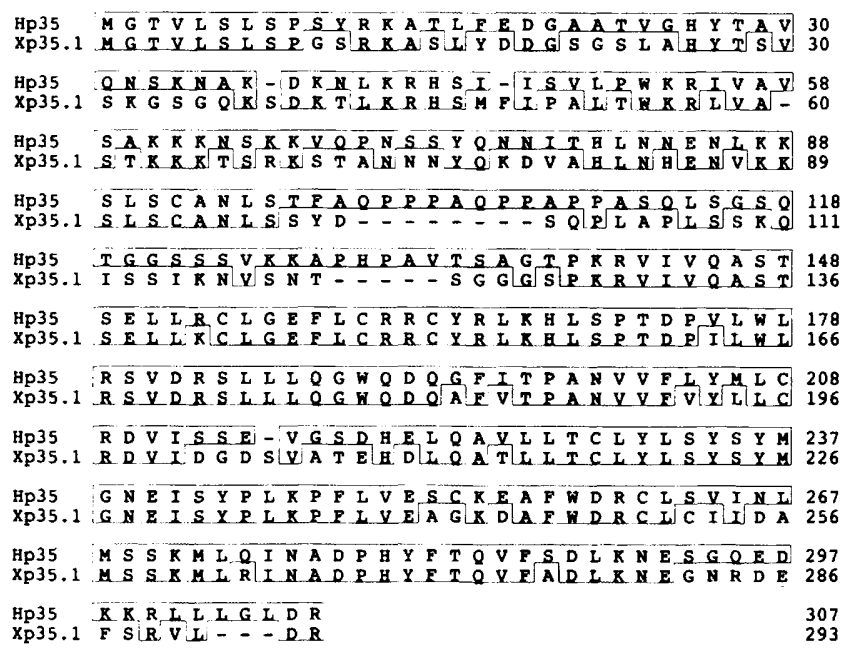

Figure 1. Xp35.1 is a novel member of the cdk5 activator family. $|A|$ The full sequence of $X p 35.1$. Both DNA and aligned amino acid sequences are shown. $(B)$ Amino acid alignment between Xp35.1 and human p35. Note that the highest degree of homology exists at the amino- and carboxyl termini of the protein while the central domain is shorter in Xp35.1 than in human p35 and shows the greatest divergence.

shown), whereas at the late neural plate stage (stage 17; Fig. 3A, panel ii) it remains over the entire expanse of the neural plate, extending over the anterior neural placode region, in cells that are as yet undifferentiated but are largely competent to form neural tissue (Coffman et al. 1993|. In addition, expression at the posterior end extends laterally compared to staining for the neuronal-specific marker NCAM (panel iv) and overlapping the region ex-

A
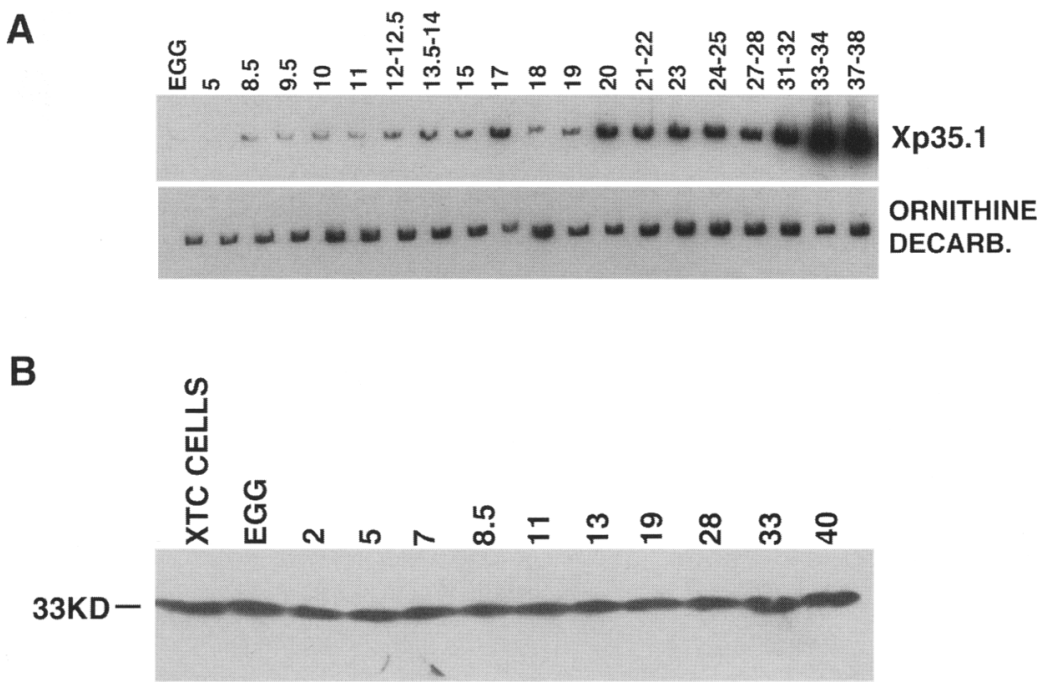

Figure 2. Developmental expression of Xp35.1 and Xcdk5. $|A|$ Two micrograms of RNA from developmentally staged embryos was reverse transcribed in a 20 - $\mu$ l reaction. One microliter per lane was used for RT-PCR analysis using primers specific for Xp35.1, (see Materials and Methods). Ornithine decarboxylase, expressed constantly through development, was also assayed as a loading control. Lanes are labeled according to developmental stage (Nieuwkoop and Faber 1967). (B) Extracts from XTC cells and developmentally staged embryos were separated by SDS-PAGE, Western blotted, and probed with a monoclonal antibody specific for cdk5 (DC17). Lanes are labeled according to developmental stage (Nieuwkoop and Faber 19671. 
Philpott et al.
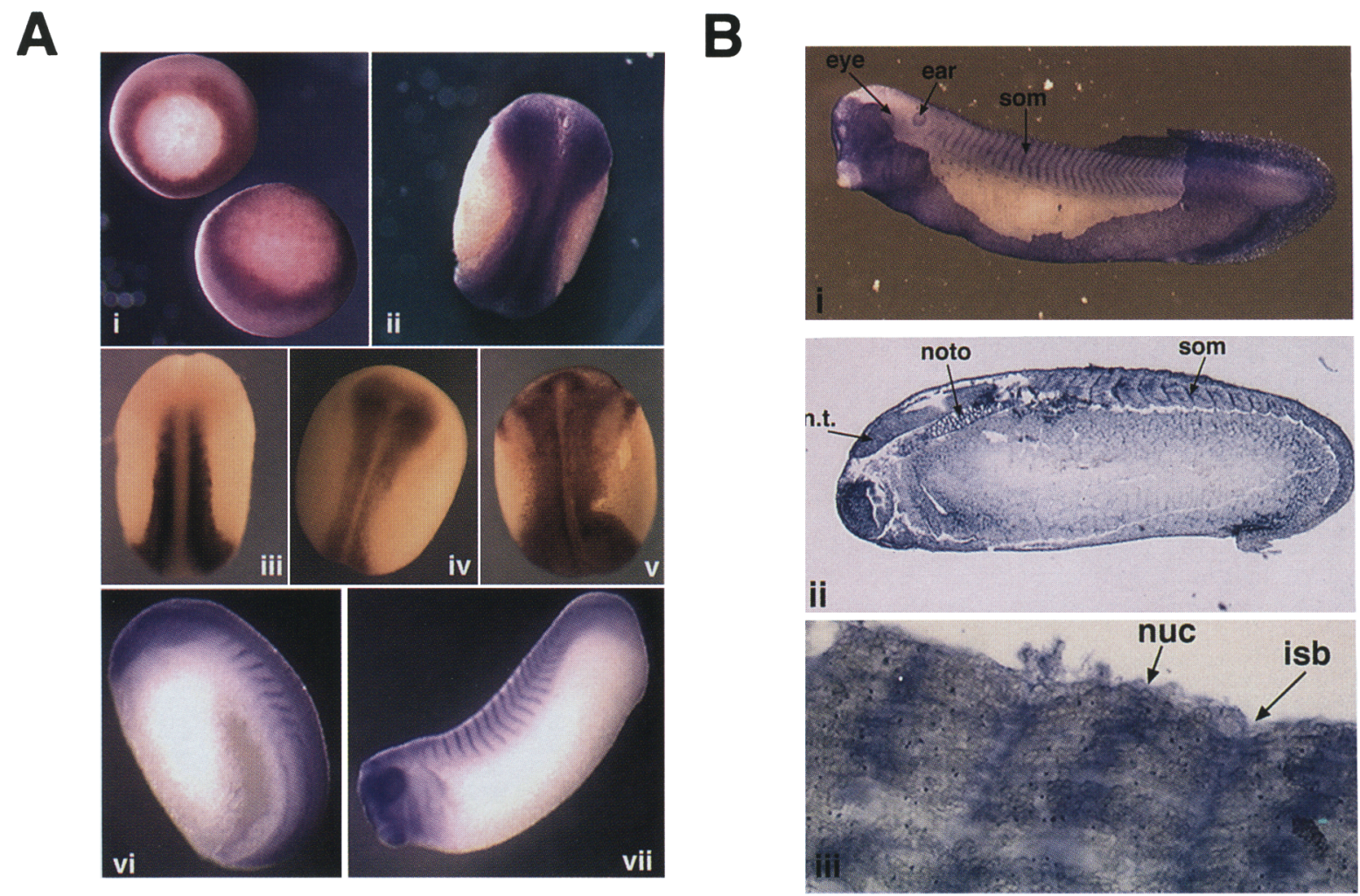

Figure 3. (A) Xp35.1 is expressed in both nerve and muscle tissue. Albino embryos were hybridized with a digoxygenin-labeled $X p 35.1$ antisense probe (panels $i, i i, v i$, and vii) or antisense probes for myoDb (iii), NCAM (iv), or Xotch (v), visualized in purple/brown. Embryonic stages are vegetal views of late blastula $(i$, lower right) or early gastrula $($ top left $)$; dorsal view of late neural plate $(i i$, iii, iv, v); lateral view of early neural tube (vi) and tailbud (vii). $(B)$ cdk5 is expressed in many embryonic tissues and is in the nuclei of somites. Embryos were stained with an antibody against the carboxyl terminus of cdk5, visualized in purple/blue. (panel i) A late tailbud embryo with the epidermis stripped away to reveal staining of the eye, ear, and somites (som), as labeled. (ii) a cdk5-stained embryo was sectioned to reveal extensive cdk5 expression including the neural tube (n.t.l, the notochord (noto), and the somites (som). (iii) A higher magnification of somites stained for $\mathrm{cdk} 5$ showing expression in the nuclei that align down the center of the somite (nuc; arrow points to aligned nuclei) and the intersomitic boundaries, the membranous boarder between somites (isb and arrow).

pressing the muscle marker MyoDb (panel iii). This staining pattern of Xp35.1 in the late neural plate stage embryo is somewhat reminiscent of that seen with Xotch (Coffman et al. 1993), the Xenopus homolog of the Drosophila gene Notch (panel v), which is thought to encompass the region competent to differentiate into both neural and dorsal mesodermal tissue (Coffman et al. 1993).

Figure 3A, panel vi, shows Xp35.1 expression in a stage 20 embryo soon after the neural tube has closed. Expression remains high in the neural tube and dorsoanterior head region, and in the dorsoposterior and tailbud regions, which includes unsegmented somitic mesoderm. In addition, at this stage in the dorsal region segmented somites have begun to form (Hamilton 1969). Single myocytes, aligned and spanning each somite, can be visualized as a row of parallel nuclei perpendicular to the central midline. These forming somites stain strongly for Xp35.1 expression. By the time the embryo has reached the mid-tailbud stage (panel vii), Xp35.1 staining is no longer prominent in the neural tube but expression is strong in segmented somites, which now extend all the way to the tailbud. In addition, expression in the head remains strong, particularly in the branchial arches, the site of migrating neural crest cells, and in the eye.

\section{Xcdk5 is expressed at high levels in developing somites and is localized to intersomitic boundaries and to the nuclei of myocytes}

Expression of the cdk5 protein was investigated by antibody staining using an affinity-purified antibody raised against the carboxyl terminus of human $\operatorname{cdk} 5$ (C8 described above; Fig. 3B). Figure 3B, panel i, shows a swimming tadpole stained for cdk 5 protein. cdk 5 is strongly expressed in the epidermis, which has been peeled away here to view underlying surface tissues. cdk5 expression is strong in the somites (som), which are largely composed of muscle myotomes in the Xenopus tadpole seen in this lateral view, with dermatome and sclerotome making only a minor contribution. In addition, cdk 5 is expressed in the ear and the eye. In Figure 3B, panel ii, sections of slightly younger embryos shows cdk 5 staining of internal tissues. cdk 5 is expressed extensively 
throughout the embryo, including the somites, the notochord, and the neural tissue. Identical results were found using a monoclonal antibody raised against human cdk5 (DC39) which cross-reacts with the Xenopus protein, and using both alkaline phosphatase and horseradish peroxidase secondary detection systems confirming specificity of the cdk5 expression pattern. Viewing cdk5 staining at higher magnification confirms that cdk5 protein is found both within nuclei that align centrally within each myotomal block (row of nuclei labeled nucl and concentrated at the intersomitic boundaries (isb). Such nuclear staining is unexpected as cdk 5 is largely confined to the cytoplasm of mammalian neurons ( $\mathrm{Ni}$ kolic et al. 1996) This nuclear localization in muscle cells raises the interesting possibility that cdk 5 may play a role in regulating nuclear functions during myogenesis.

\section{Xp35. 1 can activate cdk5 kinase activity}

cdk5 kinase can phosphorylate histone $\mathrm{Hl}$ and is predicted to have a structure similar to other members of the cdk family (Meyerson et al. 1992). By reference to other cdks, a dominant-negative mutant of cdk5 /cdk5 $\mathrm{DN}$ / has been constructed that has a single point mutation of amino acid 144 in the magnesium chelating site of the kinase from an Asp (D) to an Asn (N) (van den Heuval and Harlow 1994). This mutant can still bind to p35 but is inactive as a kinase and has been shown to act as a dominant-negative mutant by blocking the activation of endogenous cdk 5 in mammalian neuronal cultures (Nikolic et al. 1996).

The carboxy-terminal cdk5 binding and activation domain of mammalian p35 is sufficient to activate cdk5 kinase activity (Lew et al. 1992, 1994). To demonstrate that Xp35.1 can act as an activator of cdk5, RNA encoding the Xp35.1 carboxy-terminal 186 amino acids was coinjected with RNA encoding human hemaglutinin antigen (HA)-tagged cdk5 wild type (cdk5 WT) or cdk5 DN into fertilized Xenopus eggs. At the mid-gastrula stage, complexes immunoprecipitated with the anti-HA tag antibody from embryo extracts were tested for their ability to phosphorylate histone $\mathrm{Hl}$ (see Materials and Methods; Fig. 4, lanes $1-31$.

The carboxyl terminus of Xp35.1 activates the $\mathrm{Hl}$ kinase activity of coinjected HA-tagged human cdk 5 /cdk5 HA; Fig. 4, lane 2) but is unable to activate a coinjected HA-tagged human cdk5 kinase-dead dominant-negative mutant (cdk5 DN HA) (lane 3). The anti-HA antibody does not immunoprecipitate any nonspecific kinase activity from uninjected eggs (lane 1). Anti-HA immunoprecipitates from embryos injected with cdk5 WT HA that have not been coinjected with Xp35.1 show no kinase activity (data not shown), indicating that endogenous cdk5 activators are present at too low a level to activate overexpressed $\mathrm{cdk} 5$.

To determine whether Xp35.1 can activate endogenous cdk5, a similar experiment was performed by injecting RNA coding for the carboxyl terminus of Xp35.1, along with control $\beta$-galactosidase RNA or RNA encoding cdk5 DN HA into embryos, and using the antibody

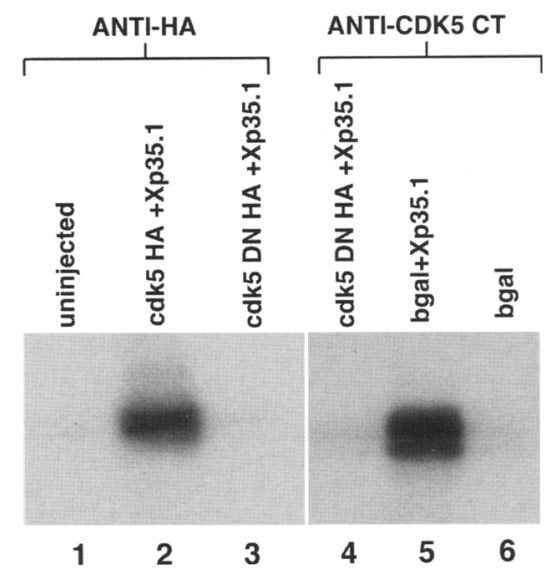

Figure 4. Xp35.1 can activate endogenous cdk5 kinase activity. Two-cell embryos were injected with the following amounts of RNA. (Lane 1) Uninjected; (lane 2) 2 ng of cdk5 WT HA with 3 ng of Xp35.1 carboxy-terminal region; (lane $312 \mathrm{ng}$ of cdk5 DN HA with 3 ng of Xp35.1 carboxy-terminal region; (lane 4) $3 \mathrm{ng}$ of cdk5 DN HA with $2 \mathrm{ng}$ of Xp35.1 carboxy-terminal region; (lane $513 \mathrm{ng}$ of $\beta$-gal with $2 \mathrm{ng}$ of Xp35.1 carboxy-terminal region; (lane 6) $5 \mathrm{ng}$ of $\beta$-gal. Embryos were allowed to develop to stage 9 , and extracts were prepared and immunoprecipitated with antibodies recognizing the HA tag on the ectopically expressed human cdk5 RNAs (lanes 1-3) or the carboxyl terminus of endogenous cdk5 (lanes 4-6), as described in Materials and Methods. Immunoprecipitates were assayed for their ability to phosphorylate histone H1, using $\left[\gamma^{-32}\right.$ P $]$ ATP.

recognizing the carboxyl terminus of cdk5 described above $(\mathrm{C} 8)$ for immunoprecipitation. The carboxy-terminal HA tag on cdk 5 DN blocks recognition by the cdk 5 carboxy-terminal antibody (data not shown), and so using this antibody for immunoprecipitation allows us to detect the kinase activity of only endogenous Xcdk5.

cdk5 immunoprecipitates from embryos injected with control $\beta$-gal RNA were unable to phosphorylate significant histone $\mathrm{H} 1$, indicating a relatively low level of intrinsic cdk5 kinase activity overall at this stage (lane 6). However, injected overexpressed Xp35.1 activates the endogenous cdk5 kinase to a high level (lane 5), and this can be blocked by coexpression with cdk5 DN (lane 4). As expected, full-length Xp35.1 is also able to activate cdk5 under the conditions described above /data not shown).

\section{Expression of cdk5 DN results in stunted embryos with disrupted somitic muscle}

To determine whether cdk5 kinase activity is required for cell differentiation in the early Xenopus embryo, we have used microinjection of RNA encoding the cdk5 DN mutant described above to block endogenous cdk5 kinase activity. RNA encoding cdk5 WT or cdk5 DN was injected into the marginal zone of both cells of a two-cell embryo, which was then allowed to develop to stage $26 /$ 27 . The two representative embryos injected with cdk 5 WT shown in Figure 5 (top two embryos) developed en- 
tirely normally compared to uninjected controls (data not shown). Internal muscle can be seen in these cleared embryos stained for the mature muscle antigen recognized by the mAb 12/101 (Kintner and Brockes 1984) and appearing dorsally as a darkly staining region. Muscle is extensive and arranged in well-defined blocks that can be distinguished within the stained myotome. In contrast to cdk5 WT injection, embryos injected with cdk5 DN (middle two embryos) were stunted and showed reduced amounts of myotomal muscle that does not appear to be well organized into well-defined blocks, which is particularly obvious in the lower cdk5 DN-injected embryo (also see Fig. 6). However, the most anterior structures of the embryos, such as the cement gland, are present, arguing against defective gastrulation. Neural defects that are evident in cdk5 DN-expressing embryos will be described elsewhere (A. Philpott, L.-H. Tsai, and M.W. Kirschner, in prep.). The rescue of the stunting and muscle disruption phenotype seen in the presence of cdk5 DN by coinjection of cdk5 WT is difficult as the amount of RNA that must be injected often exceeds the toxic limit. However, the most healthy embryos are able to tolerate even these high levels of injected RNA, and such embryos injected with cdk5 WT and cdk5 DN (bottom two embryos) are of normal length and contain extensive muscle arranged in blocks, showing that the defects in cdk5 DN-injected embryos are a specific effect of blocking cdk5 kinase activity.

To further explore the disrupted muscle phenotype seen on cdk5 DN overexpression, embryos were sectioned. As the first plane of cleavage roughly bisects the

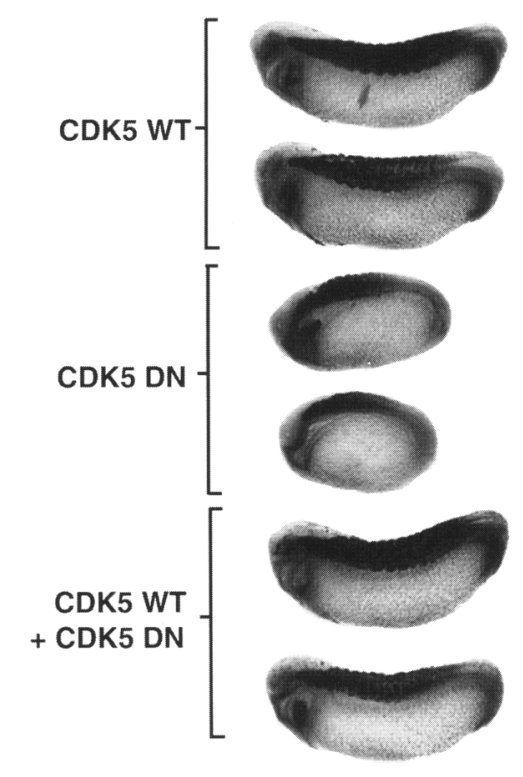

Figure 5. Embryos expressing cdk5 DN are stunted. Embryos were injected with $5 \mathrm{ng}$ of total RNA encoding wild-type cdk5 (cdk5 WT) or cdk5 dominant negative (cdk5 DN) or $5 \mathrm{ng}$ of both, as labeled, into the marginal zone of both cells of a two-cell embryo. Embryos were allowed to develop until stage 26/27 and immunostained with mAb 12/101 for mature muscle. Typical embryos were cleared for viewing.
Xenopus embryo down the left/right axis, injection into one cell of a two-cell embryo allows RNA expression in only one-half of the embryo. This leaves the other half of the embryo undisturbed, acting as a useful internal control. One cell of a two-cell embryo was injected with RNA encoding human cdk 5 WT or cdk 5 DN along with RNA encoding the lineage tracer $\beta$-gal. At the tailbud stage, embryos were stained with $\mathrm{X}$-gal, and also with the mature muscle marker mAb 12/101.

The uninjected side of the embryo (Fig. 6A, panels ii and v) shows normal muscle morphology; myotomal muscle blocks have been segregated from the presomitic mesoderm mass and are composed of an ordered array of myocytes, lying parallel to the embryonic axis, with each somite being only one cell wide. The boundaries at the dorsal and ventral region of the myotome and between myotomal blocks are well defined. Embryo halves expressing cdk5 WT (as detected by the coinjected lineage tracer $\beta$-gal, panels $i$ and iv) also contain well-ordered myotomes that are indistinguishable from the uninjected control, showing that the overexpression of cdk5 has no effect on muscle formation.

Figure 6A, panels iii and vi, shows half of an embryo expressing cdk5 DN. (The uninjected other half of this embryo is shown in panels ii and v.) Although myotomes staining with mAb $12 / 101$ are clearly present, expression of cdk5 DN results in an embryo containing disrupted muscle; in many regions myocytes are not aligned within the myotome, cells are not oriented parallel to the embryonic axis, and intermyotomal boundaries are disrupted, particularly in the ventral half.

Disruption of somitic muscle in embryos expressing cdk5 DN is strongly penetrant. In one experiment where cdk5 DN was injected bilaterally and 10 embryos were sectioned, although all 10 injected with cdk5 WT showed essentially normal muscle morphology, 9 of 10 injected with cdk 5 DN had severely disrupted myotomes while 1 showed more mild disruption, although the extent of myotomal disruption varies somewhat from experiment to experiment. cdk5 DN-expressing embryos do not appear to have a significantly altered density of nuclei in myotomes, as determined by Hoeschst DNA staining of embryo sections (data not shown).

Myotomal muscle is only one type of mesodermal tissue; the notochord, a rod-like structure lying beneath and supporting the neural tube, is also mesodermally derived but does not express Xp35.1 (Fig. 3; data not shown). To determine whether the development of the notochord is affected by blocking cdk5 kinase activity, embryos were injected with RNA encoding cdk5 WT or cdk5 DN, stained at the tailbud stage with a monoclonal antibody that recognizes a keratin sulfate antigen in the notochord (Smith and Watt 1985; Zanetti et al. 1985), and sectioned (Fig. 6B). Both cdk5 WT-expressing embryos (panels $\mathrm{i}$ and iii) and cdk5 DN-expressing embryos (panels ii and iv) contain intact and normal notochords. This indicates that while cdk 5 kinase activity is required for normal development of myotomal muscle (Figs. 5B and 6A), it is not required for the formation of another mesodermally derived tissue, the notochord (Fig. 6B). 
A

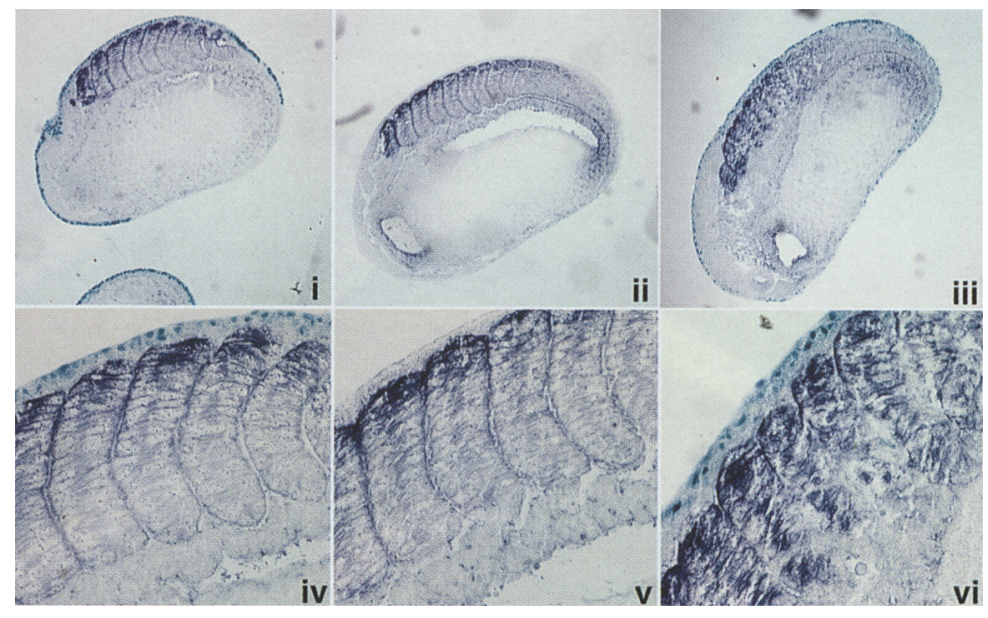

B

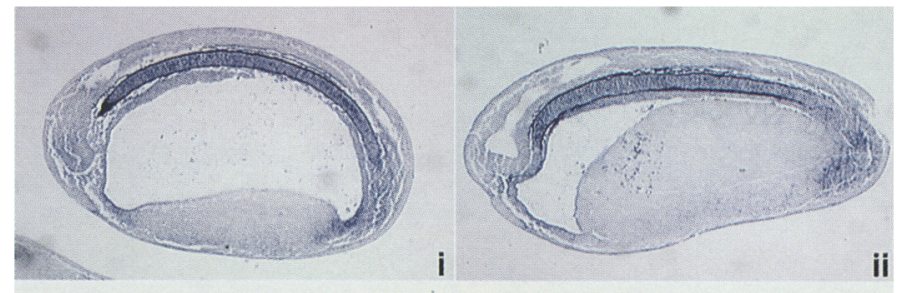

ii

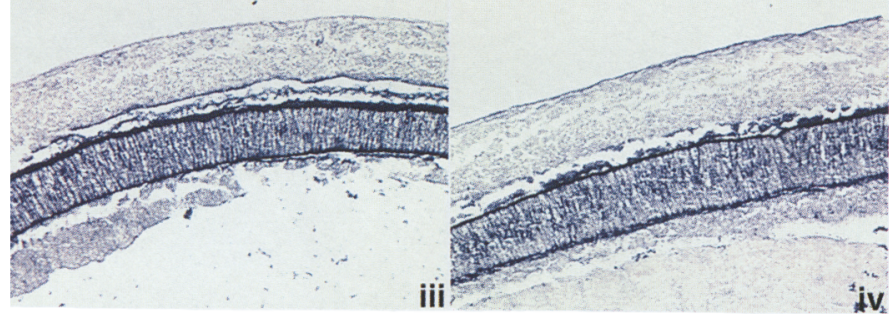

Figure 6. Blocking cdk5 kinase activity specifically disrupts somitic muscle formation. $|A|$ Somite disruption is specific for regions expressing cdk5 DN. RNA was injected into one cell of a two-cell embryo. \{Panels i,iv\} 2 ng of cdk5 WT with $0.5 \mathrm{ng}$ of $\beta$-gal; $\{i i, v\}$ uninjected side; $(i i i, v i\}$ $2 \mathrm{ng}$ of cdk5 DN with $0.5 \mathrm{ng}$ of $\beta$-gal. Embryos were allowed to develop to the early tailbud stage, then were fixed and stained for $\beta$-gal expression (turquoise; see Materials and Methods) and mature muscle with mAb 12/101 (in dark blue/purplel. Embryos were sectioned and shown at lower magnification $(i, i i, i i i)$ and at higher magnification (iV,V,Vi) of the myotomes. (B) Four-cell embryos were injected in the marginal zone of each blastomere with $5 \mathrm{ng}$ (total) of RNA encoding cdk5 WT $(i, i i i)$ or cdk 5 DN (ii,iv). Embryos were allowed to develop to the early tailbud stage and then stained in whole mount for keratin sulfate expression, using the mAb MZ15, specific for the notochord at this stage (dark blue). Embryos were sectioned to view the notochord at low $(i, i i)$ and high magnification $(i i i, i v)$.
Some defects of head neural tissue are observed in cdk 5 DN-expressing embryos (data not shown), but it seems likely, based on the disrupted brain phenotype of the $c d k 5$ and $p 35$ knockout mice, that this represents a real consequence of blocking cdk5 kinase activity and does not result from a nonspecific gastrulation defect.

\section{cdk5 kinase activity is high in tissue explants induced to form mesoderm}

Animal pole explants (animal caps) from Xenopus blastula-stage embryos have been widely used to study the induction of mesodermal tissues in isolation from other developmental events: Left untreated, caps will differentiate into ciliated epidermis, but when treated with the transforming growth factor- $\beta$ (TGF- $\beta$ ) family member activin, animal caps will elongate and differentiate into a variety of mesodermal derivatives, including muscle and notochord. We have used this assay to determine whether cdk5 kinase is activated upon mesoderm induction.

Caps were cut at stage 9 from uninjected embryos, or embryos injected with cdk5 DN RNA, and incubated with or without activin. When sibling embryos had reached stage 21 , these caps were harvested along with a sample of newly isolated caps from stage 9 embryos and assayed for cdk5 kinase activity. Caps harvested at stage 9 contain relatively high levels of endogenous cdk5 kinase activity (Fig. 7, lane 1), which is consistent with the expression of cdk5 and $X p 35.1$ in animal pole tissue at this stage (Fig. 3; data not shown). However, when caps are incubated in the absence of activin until stage 21 , cdk5 kinase activity drops fivefold as determined by PhosphoImager quantitation (lane 2). In contrast, caps treated with activin maintain high levels of kinase activity (lane 3 ). This activin-dependent cdk 5 activation is blocked completely in caps that have been injected with cdk5 DN (lane 4). This confirms the results shown in Figure 4 that human cdk5 DN injected into embryos can block endogenous cdk 5 kinase activity. Figure $7 \mathrm{~B}$ shows the morphology of the harvested animal caps described above. Untreated caps remain as round balls of epidermis, whereas treatment with activin results in elongation, indicative of mesoderm induction. Interestingly, caps injected with cdk5 DN show significantly reduced elongation in response to activin, whereas cdk5 WT-iniected caps elongate similarly to uninjected caps (data 
Philpott et al.

A
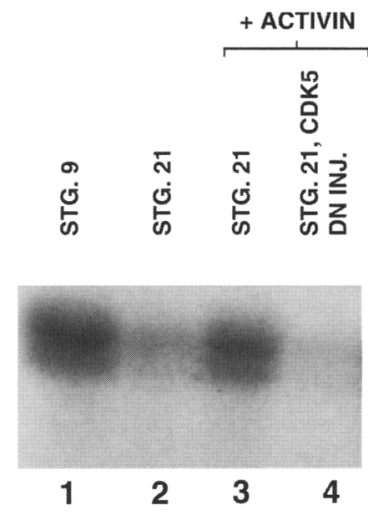

B

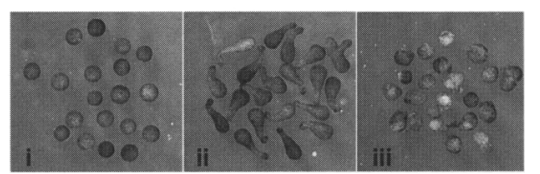

Figure 7. (A) Animal caps treated with activin have high $\mathrm{H} 1$ kinase activity. Animal caps from uninjected embryos flanes 1-3) or from embryos injected with $5 \mathrm{ng}$ of cdk5 DN RNA (lane 4) were cut from stage 9 embryos and assayed either immediately (lane 1), or after incubation without (lane 2) or with activin at $2 \mathrm{ng} / \mathrm{ml}$ (lanes 3,4) until parallel embryos had reached stage 21 (early tailbud). Extracts from caps were subjected to immunoprecipitation with the cdk5 carboxy-terminal antibody $\mathrm{C} 8$, and cdk 5 kinase activity was assayed using histone $\mathrm{H} 1$ as substrate. $(B)$ cdk5 DN blocks animal cap elongation in response to activin. Animal caps described above were photographed to record morphology when parallel embryos had reached stage 21 . (Panel i) Uninjected caps, untreated (see Fig. 6A, lane 2); (ii) uninjected caps, activin treated (see Fig. 6A, lane 3); (iii) cdk5 DN-injected caps, activin treated (see Fig. 6A, lane 4).

not shown). In light of this result, we wished to determine whether cdk5 kinase activity is required for expression of mesoderm-specific genes in response to activin.

\section{cdk5 kinase activity can regulate myogenic gene expression}

Embryos were injected with cdk5 WT or cdk5 DN alone, or cdk5 DN together with cdk5 WT or the carboxyl terminus of Xp35.1 as rescuing controls, and allowed to develop to blastula stage 8.5. Animal pole tissue explants were taken and treated with activin and cultured until sibling embryos had reached stage 18 when cDNAs were prepared and used as templates for quantitative RT-PCR analysis looking at a variety of mesodermal markers and EFl- $\alpha$ as a loading control (Fig. 8). Although untreated caps expressed no detectable muscle actin, a muscle-specific marker (lane 1), both uninjected and cdk5 WT-injected caps treated with activin expressed considerable muscle actin RNA (lanes 2,3). The somewhat reduced expression of muscle markers in caps injected with cdk5 WT relative to the uninjected control is not seen consistently between different experiments and may represent modest toxicity of injected RNA in this case; two other experiments that were quantitated showed no effect of cdk5 WT injection compared with controls. In contrast to cdk5 WT-injected caps, cdk5 DN-injected caps show substantially reduced muscle actin expression in response to activin-more than fivefold less than cdk WTinjected caps-as quantitated using PhosphorImager analysis (lane 4) in this experiment, whereas a $40 \%-50 \%$ reduction was found in two other experiments. To demonstrate specificity, we attempted to rescue this reduction in muscle marker expression by coexpression of cdk5 WT or the carboxyl terminus of Xp35.1 with cdk5 DN. Figure 8 , lanes 5 and 6 , shows that caps injected with cdk5 WT or the carboxyl terminus of Xp35.1 along with cdk5 DN have a restored ability to produce muscle actin in response to activin.

Myogenesis is regulated by a family of basic helixloop-helix (bHLH) transcription factors, including MyoD and related proteins. In Xenopus, early myogen-

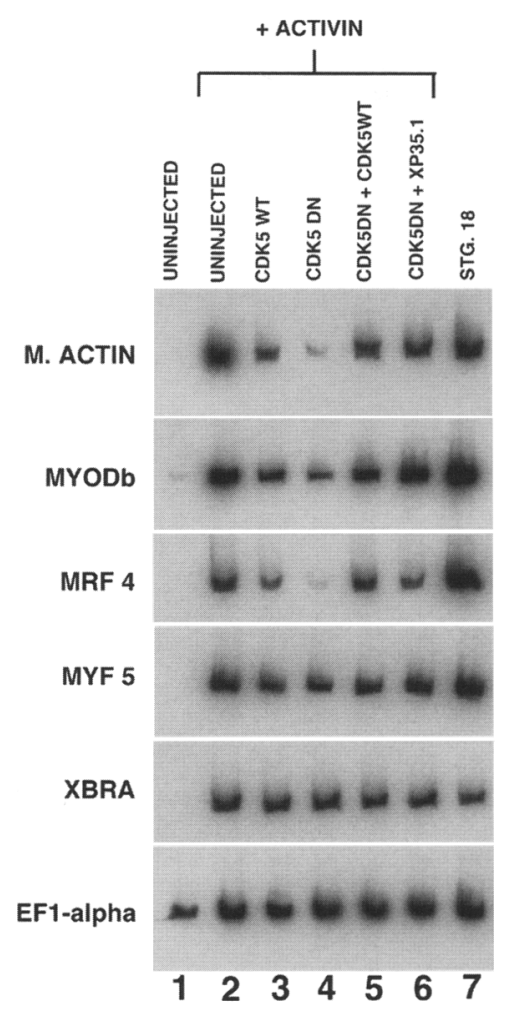

Figure 8. Blocking cdk5 kinase activity in animal cap explants down-regulates the expression of muscle markers in response to activin. Embryos were left uninjected (lanes 1,2), or injected at the two-cell stage with $5 \mathrm{ng}$ of cdk5 WT (lane 3), $5 \mathrm{ng}$ of cdk 5 $\mathrm{DN}$ (lane 4), $5 \mathrm{ng}$ of cdk5 WT with $5 \mathrm{ng}$ of cdk $5 \mathrm{DN}$ (lane 5), 5 $\mathrm{ng}$ of cdk5 DN with $5 \mathrm{ng}$ of Xp35.1 carboxy-terminal portion (lane 6). Ten animal caps were cut and incubated in buffer (lane 1) or in buffer containing $1.25 \mathrm{ng} / \mathrm{ml}$ purified activin A (lanes 2-6) for $2 \mathrm{hr}$, and then transferred to buffer alone. Caps were cultured until parallel embryos had reached stage 18 , and then harvested and analyzed for marker gene expression, as shown, by RT-PCR, described in Materials and Methods. (Lane 7) RNA from a parallel stage 18 embryo. 
esis is thought to be controlled by MyoD and Myf5 (for review, see Mohun et al. 1994) both of which are induced in response to activin (Rupp and Weintraub 1991). MRF4, another MyoD-related protein, is thought to act later in muscle maturation (Jennings 1992). We have investigated the effect of blocking cdk5 kinase activity in animal caps on expression of these myogenic factors. As expected, MyoD, Myf5, or MRF4 was not expressed in animal caps that had not been treated with activin llane 1). Uninjected caps or caps expressing cdk5 WT and treated with activin express these myogenic factors strongly (lanes 2,3 ). However, cdk5 DN-expressing caps express reduced levels of MyoD and MRF4, 2- and 6.5. fold less, respectively, compared with cdk5 WT-injected caps, which are typical results. MyoD and MRF4 expression is restored in cdk5 DN-injected caps that have been coinjected with cdk5 WT or Xp35.1 carboxyl terminus, again demonstrating specificity. Interestingly, here the expression of a third related gene, Myf5, is not affected by the expression of cdk5 DN (cf. lanes 2-4). In two out of three experiments, Myf5 expression was largely unaffected by cdk 5 DN overexpression, although the third experiment showed a 50\% drop in Myf5 levels. This variability may reflect the complex feedback relationships that exist among members of the myogenic gene family.

Blocking cdk 5 kinase activity in whole embryos disrupts formation of somitic muscle but does not seem to affect the formation of the mesodermally derived notochord. To determine whether cdk 5 kinase activity is only required for the expression of specifically muscle markers in response to activin, we looked at expression of Xbra, a pan-mesodermal marker, in these animal caps (Smith et al. 1991). Xbra is not expressed in untreated caps but is induced strongly by activin, as expected (lane 2). Interestingly, Xbra expression in response to activin is unchanged in caps injected with cdk5 WT or cdk5 DN (lanes 3,4), and this has been observed consistently. This indicates that cdk5 kinase activity is not required for the expression of all mesoderm-specific genes in response to activin but may only be required for the expression of muscle-specific genes. Moreover, cdk 5 kinase activity affects the level of some members of the myogenic bHLH family of transcription factors (MyoD, MRF4) more than others (Myf5).

\section{Overexpression of Xp35.1 results in disrupted myotomes}

Blocking cdk5 kinase activity disrupts muscle formation. We also wished to determine the effect of overexpressing its activator Xp35.1 on development of the early embryo. RNA encoding full-length Xp35.1 was injected into one cell of a two-cell embryo along with RNA encoding the lineage tracer $\beta$-gal. At tailbud stage, embryos were stained first for $\beta$-gal expression and then for expression of the mAb 12/101 muscle antigen and sectioned (Fig. 9). Expression of full-length Xp35.1, as detected by expression of the coinjected lineage tracer $\beta$-gal results in grossly disrupted muscle morphology (panel ii), often producing a complete loss of intersomitic

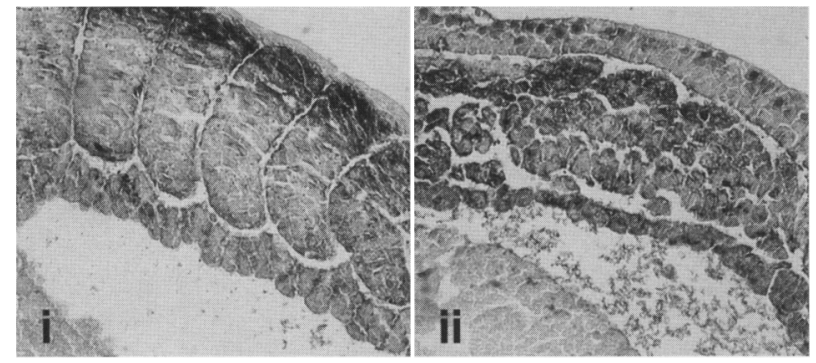

Figure 9. Xp35.1 overexpression disrupts embryonic muscle organization. One cell of a two-cell embryo was left uninjected (panel i) or injected with $2 \mathrm{ng}$ of full-length Xp35.1 with $600 \mathrm{pg}$ of $\beta$-gal RNA (ii). Embryos were fixed at early tailbud stage and stained for $\beta$-gal expression to distinguish the injected side and for mature muscle using mAb 12/101 (appears dark here). Embryos were sectioned to look at internal morphology.

boundaries and intrasomitic organization compared to the uninjected control side (panel i). Embryos bilaterally injected with full-length Xp35.1 are stunted and have substantial myotome disruption (data not shown). This confirms that $\mathrm{cdk} 5 / \mathrm{Xp} 35.1$ has an important role in muscle patterning in early Xenopus development.

\section{Discussion}

cdk5 complexed to its p35 activator has an important role in neurogenesis in mammals. This has been demonstrated both in culture, where cortical neurons expressing cdk5 DN fail to elaborate processes (Nikolic et al. 1996), and in $c d k 5$ and $p 35$ null mice, which exhibit profound neural defects (Ohshima et al. 1996; Chae et al. 1997). The status of mesoderm, however, in the $c d k 5$ knockout mice was not reported. In this paper we demonstrate a novel and unexpected role of cdk 5 kinase in the development of somitic muscle. The Xenopus embryo system is particularly well suited for studying this role because of the large size and malleability of the embryos. In addition, unlike mammalian embryos, the somitic muscle of the tadpole develops extensively before innervation occurs (stage 25-26; Muntz 1975), so muscle development can be studied in isolation from secondary effects caused by failure of the muscle to innervate properly.

Thus far, two $p 35$ homologs have been identified in mammals, p35 and p39, both of which are expressed exclusively in neurons (Tsai et al. 1994; Tang et al. 1995; Tomizawa et al. 1996; Dellale et al. 1997). We have cloned two $p 35$ homologs from Xenopus. Xp35.1 has a novel expression pattern, being found in both neural and muscle tissues (Fig. 3). In addition, while mammalian p35 and p39 are confined to differentiated cells, Xp35.1 is expressed in cells fated to become both neural and mesodermal derivatives but that are still proliferating (Coffman et al. 1993), whereas cdk 5 protein is widely expressed throughout the early embryo. cdk5 kinase activity is 
clearly found in proliferating cells in the animal caps cut at stage 9 (Fig. 7). These expression patterns indicate that cdk5, activated by $X p 35.1$, could function in differentiation or patterning of both neural and mesodermal tissues and could play a role prior to terminal differentiation.

In the Xenopus animal cap assay, explants of animal pole tissue from blastula-stage embryos can be induced to form dorsal mesoderm such as muscle and notochord in response to the mesoderm inducer activin (for review, see Slack 1994). Using this assay and a dominant-negative construct that blocks the kinase activity of endogenous cdk5, we show that cdk5 kinase activity is required for full expression of muscle actin. Myogenesis is regulated by a family of bHLH transcription factors related to MyoD. In Xenopus, the most important myogenic genes are two MyoDs [MyoDa, expressed maternally and zygotically, and $M y O D b$, expressed zygotically (Hopwood et al. 1989; Harvey 1990), Myf5 (Hopwood et al. 1991), and MRF4, the latter being proposed to have a role late in muscle maturation (Jennings 1992)]. cdk5 DN expression in activin-induced animal caps down-regulates the expression of $\mathrm{MyODb}$ and MRF4 in response to activin but has little effect on Myf5 expression. Myf5 is expressed very early in myogenesis in the frog and disappears from all but the most posterior muscle by the time the somites have formed (Hopwood et al. 1991), whereas, in contrast, MyoD remains in the maturing somites of the swimming tadpole (Hopwood et al. 1989). This observation led Hopwood and colleagues to propose that Myf5 plays a role in the very earliest stages of myogenesis, whereas the function of MyoD persists longer through somite maturation (Hopwood et al. 1991). In addition, MRF4 is proposed to function late in muscle maturation (Jennings 1992). cdk5 may function later in myogenesis to maintain myogenic gene expression via its effect on MyoD and MRF4 levels rather than at the earliest stages of myogenesis where Myf5 function may predominate.

cdk5 DN is only effective at blocking muscle actin expression in animal caps when relatively low levels of mesoderm induction by activin occurs; under these conditions, the caps in Figure 8 showed only modest cap elongation (data not shown), an indicator of the extent of mesoderm induction, even though large amounts of muscle actin was expressed. At higher activin doses, where cap elongation is extensive and presumably mesoderm induction is maximal, expression of cdk5 DN has a less dramatic effect on expression of muscle markers (data not shown). This may be attributable to a small amount of residual cdk5 kinase activity, which may be sufficient for muscle induction at higher doses of activin. However, muscle differentiation involves a highly complicated network of myogenic genes and their regulators that participate in positive feedback loops; for instance, ectopically expressed Myf5 and MyoD in animal caps are able to activate the expression of endogenous MyoD (Hopwood and Gurdon 1990; Hopwood et al. 1991). Higher activin doses may be able to overcome the inhibitory effect of cdk5 DN by activating sufficient myogenic gene expression to set up a feedback self-amplifying loop, resulting in full muscle gene expression in the absence of cdk5 kinase activity (for review, see Lassar and Munsterberg 1994).

Embryos expressing cdk5 DN are stunted. Although convergence and extension (Keller and Danilchik 1988) provides force for extension of the embryo, it seems likely that formation and maturation of the somites may also contribute significantly to anteroposterior extension (Harvey and Melton 1988). These embryos exhibit a striking disruption of myotomal muscle, particularly in the ventral region, with abnormal myotomal boundaries and chaotic myocyte organization, demonstrating a role for cdk5 kinase activity in normal muscle formation. It is not yet clear whether defects in the myotomes are secondary to defects in the induction of the myogenic genes myoD and MRF4 and, hence, are late defects in muscle differentiation, or whether they represent a separate function of cdk5 in regulating myotome patterning analogous to the role proposed for cdk5 in organization of the mammalian brain. A somewhat similar myotome disruption phenotype is observed in embryos expressing the homeobox gene Hox1A (Harvey and Melton 1988) and embryos exposed to a brief heat shock during early embryogenesis (Pearson and Elsdale 1979). These defects are not thought to be attributable to perturbation of muscle differentiation per se but to disrupt patterning of the somites directly. Staining of cdk5 DN-expressing embryos for the mature muscle marker 12/101 indicates that blocking cdk5 kinase activity alone is not enough to prevent muscle differentiation. This is not unexpected given that cdk5 DN does not block the expression of Myf5 in animal caps and Myf5 has been shown to compensate for the loss of MyoD in the MyoD knockout mouse (Rudnicki et al. 1992). Confirming the importance of $\mathrm{cdk} 5 / \mathrm{Xp} 35.1$ in regulating muscle patterning, we show that overexpression of full-length Xp35.1 produces a severe disruption of muscle organization similar to that seen with cdk5 DN. The seemingly opposite approaches of blocking cdk5 kinase activity using the dominant negative mutation, and overexpressing the $\mathrm{Xp35.1}$ activator both result in muscle disruption. Both, however, may potentially inhibit the interaction of the active kinase with its target by a competition mechanism. Alternatively, as muscle differentiation and patterning is a complex process, both overexpression and blocking of cdk5/Xp35.1 complexes may result in similar gross phenotypes through different means. However, cdk5 can have multiple partners (at least two in Xenopus) so the effect of cdk5 DN may not solely reflect its function when coupled to Xp35.1.

In summary, we have identified a novel activator of cdk5 in Xenopus, Xp35.1, which is expressed in both neural and mesodermal tissue prior to, during and after differentiation. Furthermore, we have demonstrated that cdk5 kinase activity is important for expression of the myogenic genes myoD and MRF4 in response to mesoderm inducers, and that blocking cdk5 kinase activity results in disruption of somitic muscle in the early embryo, while overexpression of Xp35.1 also disrupts muscle patterning. 


\section{Materials and methods}

\section{Library screening}

A Xenopus stage 28 head cDNA library was kindly provided by Marc Mercola (Harvard Medical School, Boston, MA; HemmatiBrivanlou et al. 1991). We used a Xenopus genomic library from Stratagene (catalog no. 946650). Plating and lifting of libraries was performed as in Sambrook et al. (1989) except filters (MSI Magna nylon transfer membranes cat. no. NOOHY 13750 l were autoclaved for $3 \mathrm{~min}$ instead of denatured and neutralized. Hybridization at low stringency was in $30 \%$ formamide, $4 \times$ SSC, $1 \times$ Denhardt's solution, $0.05 \mathrm{M} \mathrm{NaH}_{2} \mathrm{PO}_{4}(\mathrm{pH} 6.81,0.5 \% \mathrm{SDS}$, and $0.5 \mathrm{mg} / \mathrm{ml}$ of herring sperm DNA at $42^{\circ} \mathrm{C}$ overnight. The final washes were in $0.5 \times \mathrm{SSC}, 0.1 \% \mathrm{SDS}$, at $42^{\circ} \mathrm{C}$. Picking and purification of positives was performed as in Sambrook et al. (1989). High stringency hybridization was in the same solution, except with $50 \%$ formamide, and the final washes were in $0.1 \times$ $\mathrm{SSC}, 0.1 \% \mathrm{SDS}$, at $42^{\circ} \mathrm{C}$ (for primary screen) or $60^{\circ} \mathrm{C}$ (for secondaryl. Sequencing was performed with U.S. Biochemical Sequenase kit (cat. no. U570770) or by automated sequencing on an ABI 373A DNA sequencer by the Harvard Medical School biopolymers facility. Sequence analysis was performed with DNASTAR software and GCG Wisconsin Sequence Analysis Package.

\section{RACE}

RACE was performed with the GIBCO BRL 5' RACE System (cat. no. 18374-025) generally according to the kit protocol with the following exceptions. First-strand cDNA was synthesized from $1.5 \mu \mathrm{g}$ of RNA made from stage 32 embryos using $200 \mathrm{ng}$ of gene-specific primer 1 (5'-GGTAGCATCTCCTGCATAGG$\left.3^{\prime}\right)$ for reverse transcription for $1 \mathrm{hr}$ at $42^{\circ} \mathrm{C}$. After hydrolysis of RNA in $0.1 \mathrm{~N} \mathrm{NaOH}$, cDNA was dC-tailed at $37^{\circ} \mathrm{C}$ for $30 \mathrm{~min}$. One-half of the cDNA was used in the first PCR reaction with $300 \mathrm{ng}$ of anchor primer and $50 \mathrm{ng}$ of gene-specific primer 2 (5'-GAAGCTTGGACAATGACCCG-3') in a standard Taq polymerase reaction mix including $10 \%$ DMSO. The PCR was 30 cycles total, 5 at $46^{\circ} \mathrm{C}$ for annealing and 25 at $58^{\circ} \mathrm{C}$. The second round of PCR used $1 / 50$ of the first PCR as template, $50 \mathrm{ng}$ of a primer similar to the anchor primer but missing the tag and the G tail, and $50 \mathrm{ng}$ of gene-specific primer $3 / 5^{\circ}$-GATGGAGGATATCTGCTTGG $-3^{\prime}$ ) for 25 cycles with annealing at $62^{\circ} \mathrm{C}$. The third round of PCR was the same as round 2, but using $1 / 50 \%$ of the second PCR as template.

\section{Subcloning and RNA production}

Human $c d k 5$ WT and $c d k 5 D N$, van den Heuvel and Harlow 1993) were subcloned directly into the BamHI site of pCS2+ (Turner and Weintraub 1994). DNA encoding the carboxy-terminal 186 amino acids of Xp35.1 was cloned by PCR into the $B a m H I$ and EcoRI sites of pCS2+ lalong with $30 \mathrm{bp}$ of vector sequence at the $5^{\prime}$ end of the ORF). The full-length coding region of Xp35.1 was PCR cloned into the EcoRI site of 6mycpCS2+. Constructs were linearized with NotI and RNA produced from the SP6 promoter using the Message Machine kit (Ambion). RNAs were precipitated twice and redissolved in $\mathrm{RNase}$-free water. Concentration was measured by $O D_{260}$ and confirmed by ethidium bromide staining of RNA separated on agarose gels. Nuclear $\beta$-gal in pGEM blue vector (Promegal, a kind gift of Dr P. Ataliotis (University College, London, UK), was transcribed from the SP6 promoter as described above.

\section{Embryos and explants}

Embryos were injected where appropriate in $0.2 \times \mathrm{MMR} / 100 \mathrm{~mm}$
$\mathrm{NaCl}, 2 \mathrm{mM} \mathrm{KCl}, 1 \mathrm{~mm} \mathrm{MgCl}$, $2 \mathrm{mM} \mathrm{CaCl}{ }_{2}$ ) (Murray 1991), supplemented with $6 \%$ Ficoll, and transferred to $0.1 \times$ MMR after gastrulation. Animal cap explants were dissected from stage 8.5 or stage 9 embryos as stated and exposed to human activin A la kind gift of Dr. Yuzuru Eto, Ajinomoto Co., Kawasaki, Japan) at $2 \mathrm{ng} / \mathrm{ml}$ for $24 \mathrm{hr}$ (Fig. 7 ) or $1.25 \mathrm{ng} / \mathrm{ml}$ for $2 \mathrm{hr}$ (Fig. 81 in $0.5 \times$ MMR, 0.2\%BSA. Caps were transferred to $0.7 \times$ MMR, cultured until sibling embryos had reached stage 21 (Fig. 7 ) or stage 18 (Fig. 8), and processed for RT-PCR analysis or $\mathrm{H} 1$ kinase activity as outlined below. All culture solutions contained $50 \mu \mathrm{g} / \mathrm{ml}$ of gentamycin.

\section{Western blotting}

Extracts were prepared from developmentally staged embryos and XTC cells as described previously (Philpott and Friend 19941. Total protein (100 ug per lane) was separated by SDSPAGE and Western blotted to nitrocellulose by standard methods. Xcdk5 was detected using culture supernatant from the mAb DC17 (Tsai et al. 1993) for $2 \mathrm{hr}$, followed by a l-hr incubation with an anti-horseradish peroxidase-conjugated secondary antibody (Bio-Rad) at 1:2000. Antibody binding was detected using the Amersham ECL chemiluminescence detection system.

\section{H1 kinase assay}

The total amount of RNA described in the legend to Figure 4 was injected into both blastomeres of two-cell embryos, which were then allowed to develop to stage 9. Five embryos were homogenized in $30 \mu \mathrm{l}$, (Fig. 4, lanes 1-3) or 16 embryos were homogenized in $100 \mu \mathrm{l}$, (Fig. 4, lanes 4-6), of IP buffer [100 mM $\mathrm{NaCl}, 50 \mathrm{~mm} \beta$-glycerophosphate, $5 \mathrm{~mm}$ EDTA, $0.1 \%$ Triton $\mathrm{X}-100$, and $10 \mathrm{ng} / \mathrm{ml}$ each of leupeptin, pepstatin, and chymostatin [protease inhibitorsl] and centrifuged for $30 \mathrm{sec}$ at $14000 \mathrm{~g}$. The supernatants were removed and diluted threefold in IP buffer. Two microliters of anti-HA mAb (12CA5, lanes $1-3 \mid$ ascites fluid or $10 \mu \mathrm{l}$ of anti-human cdk 5 carboxy-terminal antibody $\{\mathrm{C} 8$, Santa Cruz; Fig. 4, lanes 4-6) was added, along with $30 \mu$ l of protein A-Sepharose in a $50 \%$ slurry. After incubation at $4^{\circ} \mathrm{C}$ with rocking for $3 \mathrm{hr}$, immunoprecipitates were washed five times in RIP buffer, then twice in HIK buffer 150 $\mathrm{m} M \mathrm{NaCl}, 20 \mathrm{~mm}$ HEPES: $\mathrm{KOH}$ at $\mathrm{pH} 7.2,10 \mathrm{~mm} \mathrm{MgCl}_{2}, 2 \mathrm{~mm}$ EDTA, and $0.02 \%$ Triton X-100 with protease inhibitorsl. The immunoprecipitate beads in a $50 \%$ slurry with HIK buffer were supplemented with $125 \mathrm{ng}$ of histone $\mathrm{Hl}, 87.5 \mu \mathrm{M}$ ATP, and 0.12 $\mathrm{uCi}$ of $\left[\gamma^{-32} \mathrm{P}\right] \mathrm{ATP}$ and incubated at room temperature for $1 \mathrm{hr}$. Proteins from each sample were separated by SDS-PAGE, and the dried gel was subjected to autoradiography. Extracts from animal caps (Fig. 7) were assayed for cdk5 kinase activity as described in Tsai et al. (1993) using $260 \mu \mathrm{g}$ of protein.

\section{$R T-P C R$ analysis}

RT-PCR analysis was performed as described previously (Lustig and Kirschner 1995; Lustig et al. 1996). MyoDb primer is as described by Kelley et al. (1994). Novel primer sequences are as listed below. MRF4, forward 5'-CTTTTACCTGGATGGAG-3', reverse 5'-TGGTGGGCTAAGACAT-3', producing a fragment of $\sim 160 \mathrm{bp}$ and amplified for 30 cycles. The sequences of the MRF4 primers were taken from the Xenopus molecular marker resource on the World Wide Web (http://Vize222.zo.utexas.edu) and amplified for 30 cycles. Myf5 is forward $5^{\prime}$-CCGAACCAGGGAGTCCCATG-3' and reverse 5'-GACCGCGGAAGGGAGTCAGT- $3^{\prime}$, producing a fragment of $364 \mathrm{bp}$ and amplified for 28 cycles. Xp35.1 is forward $5^{\prime}$-CATTGACAGGGACTCTGTGGC-3' and reverse $5^{\prime}$-CTGGAGAACTCATCTCGGTTG$3^{\prime}$, producing a fragment of $268 \mathrm{bp}$ and amplified for 30 cycles. 
RT-PCR of ornithine decarboxylase is described by Kinoshita et al. (1995).

\section{In situ hybridization and antibody staining}

Whole-mount in situ hybridization was performed as described by Harland (1991) using digoxigenin-11-UTP-labeled probes (Boehringer). The antisense probe for Xp35.1, amino acids 449 1014 , was synthesized using T7 RNA polymerase, with a NotIlinearized Bluescript plasmid as template. 4-Nitroblue tetrazolium chloride (NBT) and 5-bromo-4-chloro-indolyl-phosphate, 4 toluidine salt $(\mathrm{BCIP})$ were used as color substrates for the color reaction, giving purple staining.

Whole-mount antibody staining was performed in PBT (PBS, $2 \mathrm{mg} / \mathrm{ml}$ of bovine serum albumin, $0.1 \%$ Triton X-100) with $10 \%$ donkey serum using an anti-human cdk 5 carboxy-terminal affinity-purified antibody (C8, Santa Cruz) at 1:200 (Fig. 3B), purified anti-muscle mAb 12/101 (Figs. 5 and 6A; Kintner and Brockes 1984) at $1: 10$, or purified anti-keratin sulfate mAb MZ15 (Smith and Watt 1985; Zanetti et al. 1985) at 1:100 (Fig. 6B). Primary antibodies were incubated at $4^{\circ} \mathrm{C}$ overnight with rocking, then after washing for $10 \mathrm{hr}$ the secondary alkaline phosphatase-conjugated donkey anti-mouse antibody (Boehringer) was added at 1:250 overnight. After a further $8 \mathrm{hr}$ of washing, antibody staining was developed using NBT and BCIP as color substrates. Detection of $\beta$-gal activity was by the method of Vize and Melton (1991).

Embryos were fixed in MEMFA $10.1 \mathrm{M}$ MOPS at $\mathrm{pH} 7.4,2 \mathrm{~mm}$ EGTA, $1 \mathrm{mM} \mathrm{MgSO}_{4}, 3.7 \%$ formaldehyde) (Harland 1991) overnight after staining, then dehydrated and viewed cleared with benzoyl benzoate/benzoyl alcohol at 2:1 (Fig. 5) or embedded in Paraplast medium (Oxford Labware), sectioned, and mounted in Paramount (Fisher) (Figs. 6 and 9). Alternatively, myotomal muscle was stripped from a whole stained embryo, mounted under a coverslip, and viewed immediately (Fig. 3B, panel iii).

Images were obtained using incident or transillumination on a Zeiss Axiophot microscope or a Wild M8 stereoscope. All images were captured using a three-color video rate CCD camera controlled by Northern Exposure software (phase 3 imaging systems). Brightness, contrast, and color balance correction were performed using Adobe Photoshop.

\section{Acknowledgments}

We thank Dr. Yuzuru Eto for the kind gift of purified human activin A protein, Drs. Mark Mercola, Paris Ataliotis, and Karen Symes for reagents, Louise Evans for technical assistance, Robert Davis, Kristen Kroll, Kevin Lustig, and other members of the Kirschner and Tsai laboratories for invaluable discussions and technical advice. A.P. is supported by a Special Fellowship from the Leukemia Society of America. L.-H.T. is a Rita Allen Foundation Scholar. E.B.P. is supported by a National Eye Institute Graduate Training Grant.

The publication costs of this article were defrayed in part by payment of page charges. This article must therefore be hereby marked "advertisement" in accordance with 18 USC section 1734 solely to indicate this fact.

\section{References}

Chae, T., Y.T. Kwon, R. Bronson, P. Dikkes, E. Li, and L.-H. Tsai. 1997. Mice lacking p35, a neuronal specific activator of cdk5, display cortical lamination defects, seizures, and adult lethargy. Neuron 18: 29-42.

Coffmann, C.R., P. Skoglund, W.A. Harris, and C.R. Kintner. 1993. Expression of an extracellular deletion of Xotch diverts cell fate in Xenopus embryos. Cell 73: 659-671.
Dale, L. and J.M.W. Slack. 1987. Fate map for the 32-cell stage of Xenopus laevis. Development 99: 527-551.

Dellale, I., P.G. Bhide, V.S. Caviness, Jr., and L.-H. Tsai. 1997. Temporal and spatial patterns of expression of $\mathrm{p} 35$, a regulatory subunit of cyclin-dependent kinase 5 in the nervous system of the mouse. I. Neurocytol. (in press).

Gervasi C. and B.G. Szaro. 1995. The Xenopus laevis homolog to the neuronal cyclin-dependent kinase $(\mathrm{cdk} 5)$ is expressed in embryos by gastrulation. Mol. Brain Res. 33: 192-200.

Hamilton, L. 1969. The formation of somites in Xenopus. 7. Embryol. Exp. Morphol. 22: 253-264.

Harland, R.M. 1991. In situ hybridization: An improved wholemount method for Xenopus embryos. Methods Cell Biol. 36: 685-695.

Harvey, R.P. 1990. The Xenopus MyoD gene: An unlocalized maternal mRNA predates lineage-restricted expression in the early embryo. Development 108: 669-680.

Harvey, R.P. and D.A. Melton. 1988. Microinjection of synthetic Xhox-1A homeobox RNA disrupts somite formation in developing Xenopus embryos. Cell 53: 687-697.

Hemmati-Brivanlou, A., J.R. de la Torre, C. Holt, and R.M. Harland. 1991. Cephalic expression and molecular characterization of Xenopus En-2. Development 111: 715-724.

Hopwood, N.D. and J.B. Gurdon. 1990. Activation of muscle genes without myogenesis by ectopic expression of MyoD in frog embryo cells. Nature 347: 197-200.

Hopwood, N.D., A. Pluck, and J.B. Gurdon. 1989. MyoD expression in the forming somites is an early response to mesoderm induction in Xenopus embryos. EMBO I. 8: 3409-3417.

- 1991. Xenopus Myf-5 marks early muscle cells and can activate muscle genes ectopically in Xenopus embryos. Development 111: 551-560.

Isaacs, H.V., D. Tannahill, and J.M.W. Slack. 1992. Expression of a novel FGF in the Xenopus embryo. A new candidate inducing factor for mesoderm formation and anteroposterior specification. Development 114: 711-720.

Ishiguro, K., S. Kobayashi, A. Omore, M. Takamatsu, S. Yonekura, K. Anzai, K. Imahori, and T. Uchida. 1994. Identification of the $23 \mathrm{kDa}$ subunit of tau protein kinase II as a putative activator of $\mathrm{cdk} 5$ in bovine brain. FEBS Lett. 342: 203-208.

Jennings, C.G.B. 1992. Expression of the myogenic gene MRF4 during Xenopus development. Dev. Biol. 150: 121-132.

Keller R. and M. Danilchik. 1988. Regional expression, pattern and timing of convergence and extension during gastrulation of Xenopus laevis. Development 103: 193-209.

Kelley, C., K. Yee, R. Harland, and L.I. Zon. 1994. Ventral expression of GATA-1 and GATA-2 in the Xenopus embryo defines induction of hematopoietic mesoderm. Dev. Biol. 165: 193-205.

Kinoshita, N., J. Minshull, and M.W. Kirschner. 1995. The identification of two novel ligands of the FGF receptor by a yeast screening method and their activity in Xenopus development. Cell 83: 621-630.

Kintner, C.R. and J.P. Brockes. 1984. Monoclonal antibodies identify blastema cells derived from dedifferentiating muscle in newt limb regeneration. Nature 308: 67-69.

Lassar, A. and A. Munsterberg. 1994. Wiring diagrams: Regulatory circuits and the control of skeletal myogenesis. Curr. Opin. Cell Biol. 6: 432-442.

Lew, J., K. Beaudette, C.M.E. Litwin, and J.H. Wang. 1992. Purification and characterization of a novel proline-directed protein kinase from bovine brain. J. Biol. Chem. 267: 1338313390.

Lew, J., Q.-Q. Huang, R.J. Winkfein, Z. Qi, R. Aebersold, T. Hunt, and J.H. Wang. 1994. Neuronal cdc2-like kinase is a 
complex of cyclin-dependent kinase 5 and a novel brainspecific regulatory subunit. Nature 371: 423-425.

Lustig, K.D. and M.W. Kirschner. 1995. Use of an oocyte expression assay to reconstitute inductive signaling. Proc. Nat1. Acad. Sci. 92: 6234-6238.

Lustig, K.D., K. Kroll, E. Sun, R. Ramos, H. Elmendorf, and M.W. Kirschner. 1996. A Xenopus nodal-related gene that acts in synergy with noggin to induce complete secondary axis and notochord formation. Development 122: 32753282.

Meyerson, M., G.H. Enders, C.-L. Wu, L.-K. Su, C. Gorka, C. Nelson, E. Harlow, and L.-H. Tsai. 1992. A family of human cdc2-related protein kinases. EMBO J. 11: 2909-2917.

Mohun, T., R. Wilson, E. Gionti, and M. Logan. 1994. Myogenesis in Xenopus laevis. Trends Cardiac Med. 4: 146-151.

Muntz, L. 1975. Myogenesis in the trunk and leg during development of the tadpole of Xenopus laevis (Daudin 1802). I. Embryol. Exp. Morphol. 33: 757-774.

Murray, A. 1991. Cell cycle extracts. Methods Cell Biol. 36: 581-605.

Newport, J.W. and M.W. Kirschner. 1982. A major developmental transition in Xenopus embryos. II. Control of the onset of transcription. Cell 30: 687-696.

Nieuwkoop, P.D. and J. Faber. 1967. Normal table of Xenopus laevis (Daudin). North Holland, Amsterdam, The Netherlands.

Nikolic, M., H. Dudek, Y.T. Kwon, Y.F.M. Ramos, and L.-H. Tsai. 1996. The cdk5/p35 kinase is essential for neurite outgrowth during neuronal differentiation. Genes \& Dev. 10: $816-825$

Ohshima, T., J.M. Ward, C.-G. Huh, G. Longenecker, Veeranna, H.C. Pant, R.O.Brady, L.J. Martin, and A.B. Kulkami. 1996. Targeted disruption of the cyclin-dependent kinase 5 gene results in abnormal corticogenesis, neuronal pathology and perinatal death. Proc. Nat. Acad. Sci. 93: 11173-11178.

Pearson, M. and T. Elsdale. 1979. Somitogenesis in amphibian embryos. I. Experimental evidence for an interaction between two temporal factors in the specification of somite pattern. J. Embryol. Exp. Morphol. 51: 27-50.

Philpott, A. and S.H. Friend. 1994. E2F and its developmental regulation in Xenopus laevis. Mol. Cell Biol. 14: 5000-5009.

Rudnicki, M.A., T. Braun, S. Hinuma, and R. Jaenisch. 1992. Inactivation of $\mathrm{MyoD}$ in mice leads to upregulation of the myogenic HLH gene Myf-5 and results in apparently normal mouse development. Cell 71: 383-390.

Rupp, R.A.W. and H. Weintraub. 1991. Ubiquitous MyoD transcription at the midblastula transition precedes inductiondependent MyoD expression in presumptive mesoderm of X. laevis. Cell 65: 927-937.

Sambrook, J., E.F. Fritsch, and T. Maniatis. 1989. Molecular cloning: A laboratory manual, 2nd ed. Cold Spring Harbor Laboratory Press, Cold Spring Harbor, NY.

Shetty, K.T., W.T. Link, and H.C. Pant. 1993. Cdc2-like kinase from rat spinal cord specifically phosphorylates KSPXX motifs in neurofilament proteins: Isolation and characterization. Proc. Nat. Acad. Sci. 90: 6844-6848.

Slack, J.M.W. 1994. Inducing factors in Xenopus early embryos. Curr. Biol. 4: 116-126.

Smith, J.C. and F.M. Watt. 1985. Biochemical specificity of the Xenopus notochord. Differentiation 29: 109-115.

Smith, J.C, B.M.J. Price, J.B.A. Green, D. Weigel, and B.G. Herrmann. 1991. Expression of a Xenopus homolog of brachyury $(\mathrm{T})$ is an immediate-early response to mesoderm induction. Cell 67: 79-97.

Tang, D., J. Yeung, K.-Y. Lee, M. Matsushita, H. Masui, K. Tomizawa, O. Hatase, and J.H. Wang. 1995. An isoform of the neuronal cyclin-dependent kinase $5(\mathrm{cdk} 5)$ activator. I. Biol. Chem. 270: 26897-26903.

Tomizawa, K., H. Matsui, M. Matsushita, J. Lew, M. Tokuda, T. Itano, R. Konishi, J.H. Wang, and O. Hatase. 1996. Localization and developmental changes in the neuron-specific cyclin-dependent kinase 5 activator (p35(NCK5A) in the rat brain. Neuroscience 74: 519-529.

Tsai, L.-H., T. Takahashi, V.S. Caviness, Jr., and E. Harlow. 1993. Activity and expression pattem of cyclin-dependent kinase 5 in the embryonic mouse nervous system. Development 119: 1029-1040.

Tsai, L.-H., I. Delalle, V.S. Caviness, Jr., T. Chae, and E. Harlow. 1994. p35 is a neural-specific regulatory subunit of cyclindependent kinase 5. Nature 371: 419-423.

Turner, D.L. and H. Weintraub. 1994. Expression of achaetescute homolog 3 in Xenopus embryos converts ectodermal cells to a neural fate. Genes \& Dev. 8: 1434-1447.

van den Heuval, S. and E. Harlow. 1993. Distinct roles for cyclin-dependent kinases in cell cycle control. Science 262: 2050-2054.

Vize, P.D. and D.A. Melton. 1991. Assay for gene function in developing Xenopus embryos. Methods Cell Biol. 36: 367-387.

Zanetti, M., A. Ratcliffe, and F.M. Watt. 1985. Two subpopulations of differentiated keratinocytes identified with a monoclonal antibody to keratin sulphate. J. Biol. Chem. 101: 53-59. 


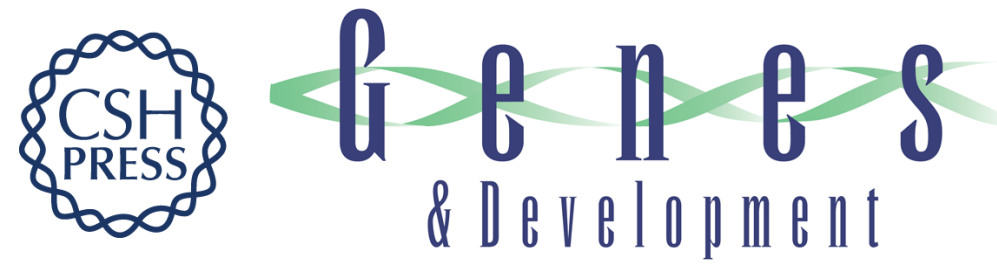

\section{The role of cyclin-dependent kinase 5 and a novel regulatory subunit in regulating muscle differentiation and patterning.}

A Philpott, E B Porro, M W Kirschner, et al.

Genes Dev. 1997, 11:

Access the most recent version at doi:10.1101/gad.11.11.1409

References This article cites 47 articles, 17 of which can be accessed free at:

http://genesdev.cshlp.org/content/11/11/1409.full.html\#ref-list-1

License

Email Alerting

Service

Receive free email alerts when new articles cite this article - sign up in the box at the top right corner of the article or click here.

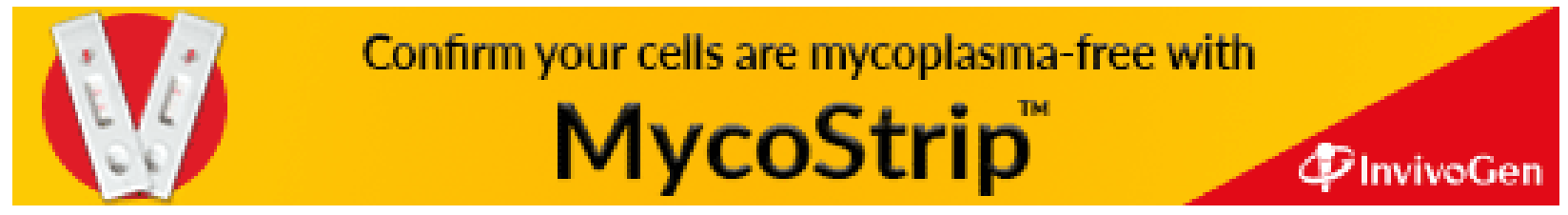

